\title{
Unraveling the Structural Transformation of Wood Lignin During Deep Eutectic Solvent Treatment
}

\begin{abstract}
Shuizhong Wang ${ }^{1+}$, Helong $\mathrm{Li}^{1+}$, Ling-Ping Xiao ${ }^{2,3 *}$ and Guoyong Song ${ }^{1 *}$
${ }^{1}$ Beijing Key Laboratory of Lignocellulosic Chemistry, Beijing Advanced Innovation Center for Tree Breeding by Molecular Design, Beijing Forestry University, Beijing, China, ${ }^{2}$ Liaoning Key Laboratory of Pulp and Paper Engineering, Center for Lignocellulose Chemistry and Biomaterials, School of Light Industry and Chemical Engineering, Dalian Polytechnic University, Dalian, China, ${ }^{3}$ Guangxi Key Laboratory of Clean Pulp and Papermaking and Pollution Control, College of Light Industry and Food Engineering, Guangxi University, Nanning, China
\end{abstract}

OPEN ACCESS

Edited by:

Chang Geun Yoo,

SUNY College of Environmental Science and Forestry, United States

Reviewed by:

Wen Wang,

Guangzhou Institute of Energy Conversion (CAS), China

Qiong Wang,

Guangzhou Institute of Energy Conversion (CAS), China

${ }^{*}$ Correspondence:

Ling-Ping Xiao

Ipxiao@dlpu.edu.cn

Guoyong Song

songg@bjfu.edu.cn

tThese authors have contributed equally to this work

Specialty section:

This article was submitted to Bioenergy and Biofuels,

a section of the journal

Frontiers in Energy Research

Received: 12 February 2020

Accepted: 10 March 2020

Published: 14 April 2020

Citation:

Wang S, Li H, Xiao L-P and Song G (2020) Unraveling the Structural Transformation of Wood Lignin During Deep Eutectic Solvent Treatment.

Front. Energy Res. 8:48.

doi: 10.3389/fenrg.2020.00048
Deep eutectic solvents (DESs) can efficiently promote the efficiency of cellulose enzymatic hydrolysis through the removal of lignin component in lignocellulosic biomass pretreatment. Unraveling the fundamental structural variant of lignin during DES treatment would facilitate to understand the DES-based biomass pretreatment in a clear perspective. Herein, an enzymatic mild acidolysis lignin (EMAL) and a series of $\beta-O-4$ lignin model compounds were employed to be treated with choline chloride $(\mathrm{ChCl}) /$ lactic acid (LA) (1:2) DES, from which the structural variant of all lignin fractions can be realized in a detailed version. The $\beta$-O-4 linkages, existing in either realistic lignin or model compounds, could be cleaved by $\mathrm{ChCl} / \mathrm{LA}$, thus leading to the decrease of molecular weight and the rise of hydroxyl groups. The influence of reaction temperature and time was also examined in view of some key structural parameters. Experimental evidences from model compounds confirmed that the repolymerization occurs with the depolymerization of lignin, which may account for the low production of monomeric products during DES treatment.

\section{Keywords: lignin, deep eutectic solvents (DESs), $\beta-0-4$ mimics, repolymerization, depolymerization}

\section{INTRODUCTION}

Lignocellulosic biomass, which possesses cellulose (ca. 30-50 wt\%), hemicellulose ( $c a .20-30 \mathrm{wt} \%$ ), and lignin ( $c a .15-30 \mathrm{wt} \%$ ), is recognized as a complementary and alternative hydrocarbon resource to fossil feedstocks (Tuck et al., 2012; Galkin and Samec, 2016). In current biorefineries, the pretreatment of biomass, which aims to remove the lignin and promote the efficiency of cellulose enzymatic hydrolysis, remains an essential step (Behera et al., 2014; Rastogi and Shrivastava, 2017). The efforts at developing novel and efficient pretreatment technologies still stay an important one. Recently, deep eutectic solvents (DESs) have gained considerable attention as a new medium for biomass pretreatment due to their significant merits, including ease to prepare, stable chemical property, low cost, recyclability, and environment amity (Mbous et al., 2017; Satlewal et al., 2018). DESs are a mixture of a hydrogen bonding donor (HBD) and a hydrogen bonding acceptor (HBA), which present analogous solvent characteristics with ionic liquids (ILs) (Zhang et al., 2012; Smith et al., 2014). In DESs, the lignin and hemicellulose components can be deconstructed and removed 
from biomass matrix, while cellulose component can survive because of strong hydrogen bonding networks and stable cohesive energy (Vigier et al., 2015). Pioneering works have indicated that DES pretreatment can significantly promote the efficacy of residue cellulose enzymatic hydrolysis. The plant species, which on the pretreatment with different DESs, have been extended to gramineae [corncob (Procentese et al., 2015; Zhang et al., 2016), wheat straw (Jeong et al., 2015), sorghum (Das et al., 2018), and switchgrass (Chen et al., 2018; Kim et al., 2018)], hardwood [eucalyptus (Shen et al., 2019), willow (Lyu et al., 2018; Song et al., 2019), and poplar (Alvarez-Vasco et al., 2016; Liu et al., 2017)], softwood [pine (Lynam et al., 2017), spruce (Wahlström et al., 2016), and fir (Alvarez-Vasco et al., 2016)], and endocarp (Li et al., 2018).

Lignin is the only renewable aromatic hydrocarbon resource, and biorefinery industries have pursued efficient means for lignin valorization for more than a century (Ragauskas et al., 2014; Sun et al., 2018; Song, 2019; Wu et al., 2019; Zhang et al., 2019). Upon the treatment of biomass with DESs, lignin in lignocellulosic biomass matrix can be cleaved and solubilized (Satlewal et al., 2018). In such a process, more structural complexity has been added to chemical properties of DES-extracted lignin compared to its native version, and this would influence the subsequent upgrading of lignin remarkably. Zhang et al. illustrated that choline chloride (ChCl)/lactic acid (LA) (1:2 molar ratio) DES was capable of extracting lignin with low molecular weight $\left(\mathrm{M}_{\mathrm{W}}\right)$ from poplar and Douglas fir trees, and they suggested that DES served as an acidic catalyst to rupture $\beta-\mathrm{O}-4$ lignin linkages without subsequent condensation reactions (AlvarezVasco et al., 2016). Shi et al. reported that all ether linkages in sorghum straw lignin were ruptured with $\mathrm{ChCl} / \mathrm{LA} \mathrm{DES}$, and the resulting lignin could be depolymerized into monophenols with $\mathrm{Ru} / \mathrm{C}$ catalyst efficiently (Das et al., 2018). Singh et al. used the DESs from lignin-derived monophenols to treat switchgrass; instead, they found that major ether linkages still remained intact in the residual lignin after pretreatment/saccharification (Kim et al., 2018). Wan et al. used ternary DESs to treat switchgrass, which led to the removal of lignin and hemicellulose efficiently; depolymerization and repolymerization of lignin were corroborated on the analysis of NMR spectra (Chen et al., 2019). Obviously, different views on whether repolymerization reaction of lignin occurs or not in DES-pretreated biomass were both taken on in the past. Moreover, it is worthy to point out that only partial lignin fraction could be recovered and characterized in DES biomass pretreatment, thus leaving other lignin fractions in an unknown state. From the pretreatment of biomass and valorization of lignin viewpoints, the deep insight into lignin structural transformation with DES is great of interest and importance.

Herein, we used enzymatic mild acidolysis lignin (EMAL), derived from Eucalyptus tree, as well as dimeric and polymeric $\beta$-O-4 lignin models to undergo the treatment of $\mathrm{ChCl} / \mathrm{LA}$ DES. The whole lignin fractions (i.e., regenerated and fragmented lignin) derived from DES treatment could be retrieved for investigation. Based on the NMR, gel permeation chromatography (GPC), gas chromatography (GC)-mass spectrometry (MS), liquid chromatography (LC)-mass spectrometry (MS), and biomass compositional analysis, the variations of lignin with reaction temperature and time were established in terms of $\mathrm{M}_{\mathrm{w}}$, monomeric products, as well as the abundance linkages and hydroxyl group. The profound comprehension on lignin structural transformation unraveled the depolymerization and repolymerization pathways of lignin during the treatment of DES.

\section{MATERIALS AND METHODS}

\section{Materials}

Eucalyptus grandis (5 years old) were obtained from Guangxi Province, China. Eucalyptus EMAL was isolated according to the procedure developed by Wu and Argyropoulos (2003). The lignin chemical composition was measured according to NREL/TP510-42618 protocol described previously (Sluiter et al., 2008). Polymeric and dimeric model compounds were synthesized according to our previous report (Li and Song, 2019), such as: dimeric model compound 1a had a complete $\beta$-O-4 structure and a phenolic group, dimeric model compound $\mathbf{1 b}$ had a complete $\beta-\mathrm{O}-4$ structure but lacked a non-phenolic group, dimeric model compound 1c was a phenolic model but was lacking $\gamma-\mathrm{CH}_{2} \mathrm{OH}$ in the $\beta$-O-4 structure, dimeric model compounds phenethoxybenzene and 2-phenoxy-1-phenylethanol had no complete $\beta-\mathrm{O}-4$ structure and methoxyl group on aromatic ring. $\mathrm{ChCl}$ and LA, purchased from Energy Chemical, were used for the preparation of DES in a 1:2 ratio without further purification. Commercial cellulase and xylanase were obtained from Shandong Longcott Enzyme Preparation Co., Ltd., China.

\section{Treatment of Lignin With Deep Eutectic Solvent}

EMAL $(0.2 \mathrm{~g})$ and ChCl/LA DES (2.0 g) were loaded in a $20-\mathrm{ml}$ reactor, which was heated to the desired reaction temperature for a certain time with magnetic stirring (500 rpm). After the reaction, the reactor was cooled, and the thick reaction mixture was diluted with ethanol $(5 \mathrm{ml})$. The addition of $\mathrm{HCl}$ solution $(\mathrm{pH}=2)$ led to a precipitate, which was on the treatment of centrifugation, washing with ethanol/water (v/v, 1:9), and freeze-drying to afford regenerated lignin (RL). The liquid fraction from centrifugation was extracted with dichloromethane to obtain fragmented lignin samples (FL) in organic phase. The detailed post-processing flowchart of lignin treatment with DES was shown in Figure 1. The obtained regenerated and fragmented lignin samples were characterized by NMR [two-dimensional (2D) heteronuclear single quantum coherence spectroscopy (HSQC) and ${ }^{31} \mathrm{P}$ ], GPC, and GC-MS analysis. The used DES existed in the water phase after dichloromethane extraction, which could be recycled by the removal of water under vacuum conditions.

\section{Analytic Methods}

The NMR spectra were acquired on a Bruker AVANCE 400 $\mathrm{MHz}$ spectrometer by using a lignin sample $(50 \mathrm{mg})$ dissolved in DMSO- $d_{6}(0.5 \mathrm{ml})$. HSQC cross peaks and ${ }^{31} \mathrm{P}$ signals were assigned by comparing the spectra with the literatures (Brosse et al., 2010; Mansfield et al., 2012; Wang et al., 2017; Xiao et al., 


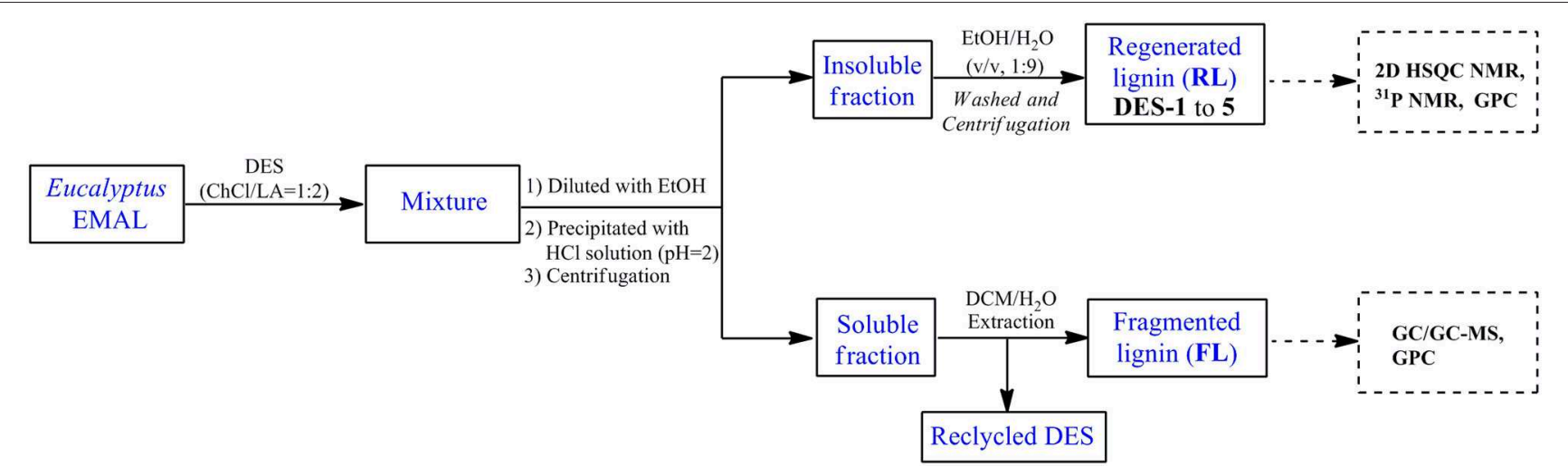

FIGURE 1 | The post-processing flowchart of lignin treatment with deep eutectic solvent (DES).

2017; Meng et al., 2019; Yang et al., 2020). GPC analysis of lignin samples [tetrahydrofuran (THF) solution, ca. $2 \mathrm{mg} / \mathrm{ml}$ ] was performed on Shimadzu LC-20AD equipped with a PL-gel $10 \mu \mathrm{m}$ Mixed-B $7.5 \mathrm{~mm}$ ID column (mixed) and UV detection detector $(254 \mathrm{~nm})$ at $50^{\circ} \mathrm{C}$, using THF as the solvent $(1 \mathrm{ml} / \mathrm{min})$, which was calibrated with polystyrene standards (peak average $\mathrm{M}_{\mathrm{w}}$ values of 96, 500, 1,320, 9,200, 66,000 g/mol; Polymer Laboratories Ltd.). GC-MS analysis of fragmented lignin samples was performed on Shimadzu GC-MS-QP2010SE equipped with an HP-5 MS ( $30 \mathrm{~m} \times 250 \mathrm{~mm} \times 0.25$; Agilent $)$ capillary column and a mass spectroscopy detector. LC-MS analysis of DEStreated dimeric compound was performed on Agilent 1290-6460 equipped with SB-C18 and electrospray ionization (ESI). The column oven was held at $30^{\circ} \mathrm{C}$ during analysis process. The mobile phase was a gradient methanol/water (with $0.1 \%$ formic acid and $5 \mathrm{mM}$ ammonium acetate) at $0.2 \mathrm{ml} / \mathrm{min}$ flow rate.

\section{RESULTS AND DISCUSSION}

\section{The Treatment of Enzymatic Mild Acidolysis Lignin With Choline Chloride/Lactic Acid Deep Eutectic Solvent}

An EMAL isolated from Eucalyptus was selected as a substrate (Guerra et al., 2006; Xiao et al., 2017; Wang et al., 2018). The total lignin and carbohydrate contents were measured as about $87 \mathrm{wt} \%$ and $7 \mathrm{wt} \%$ based on biomass compositional analysis (Table S1). 2D HSQC NMR spectra analysis indicated this EMAL featured abundant $\beta-\mathrm{O}-4$ linkages (64\%), as well as less $\beta-\beta$ (3\%) and $\beta-5(10 \%)$ substructures, being kin to native lignin in biomass (Figure 2A). Thereby, this EMAL is a suitable substrate to unravel the lignin structural variation. After the treatment of EMAL with $\mathrm{ChCl} / \mathrm{LA}$ DES (1:2 of molar ratio), the reaction mixture was diluted with $\mathrm{EtOH}$ and $\mathrm{HCl}$ solution $(\mathrm{pH}=2)$, thus leading to obtain regenerated lignin (RL, DES-1 to DES-5) as a precipitate. The leftover soluble fraction contained fragmented lignin (FL) species and DES, which could be separated by dichloromethane/water extraction (Figure 1). The analysis of ${ }^{1} \mathrm{H}$ NMR spectra indicated no changing on the recycled DES (90\%) (Figure S1). The detailed yields of RL and FL obtained at different reaction temperatures and times were presented in
Table 1. With $80^{\circ} \mathrm{C}$ and $1 \mathrm{~h}$ treatment, $86 \%$ of RL (DES-1) and $10 \%$ of FL were obtained, respectively (Table 1, entry 2). The high mass balance (96\%) indicated that all lignin fractions could be basically recovered for characterization. Thereby, the utilization of isolated EMAL can overcome the limitation in the biomass pretreatment by DES, wherein the illustration of the lignin variation is incomplete. With the rise of reaction temperature, the decreasing of $\mathbf{R L}$ and increasing of $\mathbf{F L}$ were observed simultaneously, as seen in the case of $100^{\circ} \mathrm{C}(83 \%$ and $16 \%$; Table 1, entry 3$), 120^{\circ} \mathrm{C}(73 \%$ and $23 \%$; Table 1, entry 4) and $140^{\circ} \mathrm{C}(71 \%$ and $20 \%$; Table 1, entry 5). This scenario may be because the harsher reaction condition enhances the fragmentation of lignin into small and soluble pieces. A similar trend was also observed at variable reaction times at $100^{\circ} \mathrm{C}$, that is, prolonging the treatment time led to the low yield of $\mathbf{R L}$ and high yield of FL (Table 1, entries 6 and 7). The detailed structural changes to the EMAL were then assessed by GC-MS, GPC, and NMR spectroscopy.

\section{NMR Analysis}

The abundance of hydroxyl group $(\mathrm{OH})$ plays a critical role in future lignin valorization ( $\mathrm{Li}$ and Song, 2019), which would be alternated with the cleavage of $\beta-\mathrm{O}-4$ linkages and condensation reaction. To assess the variations of $\mathrm{OH}$ after DES treatment, regenerated lignin samples were treated with a phosphorylation reagent [2-chloro-4,4,5,5-tetramethyl-1,3,2dioxaphospholate (TMDP)] and analyzed by typical ${ }^{31} \mathrm{P}$ NMR technology (Brosse et al., 2010; Wang et al., 2017; Meng et al., 2019; Yang et al., 2020). The aliphatic OH (145.5-149.5 ppm), condensed phenolic OH (S unit, 143.5-144.5 ppm; G unit, 140.8-141.2), uncondensed phenolic $\mathrm{OH}$ (S unit, 141.8-143.5 ppm; G unit, 138.5-140.5) from syringyl and guaiacyl units, as well as carboxylic group (134.5-135.5 ppm) were all measured (Table 1; see also Figure S2). The abundance of aliphatic $\mathrm{OH}$ tapered off with the increasing of reaction temperature and time because the cleavage of $\beta$-O-4 linkages resulted in the loss of $\mathrm{C}_{\alpha^{-}}$ $\mathrm{OH}$ moiety. On the contrary, the total phenolic $\mathrm{OH}$ gradually increased with higher reaction temperature or longer time, which derived from the exposing of phenolic $\mathrm{OH}$ after the cleavage of $\beta$-O-4 linkages. The non-condensed $\mathrm{OH}$ for DES-1 $\left(80^{\circ} \mathrm{C}\right.$, 


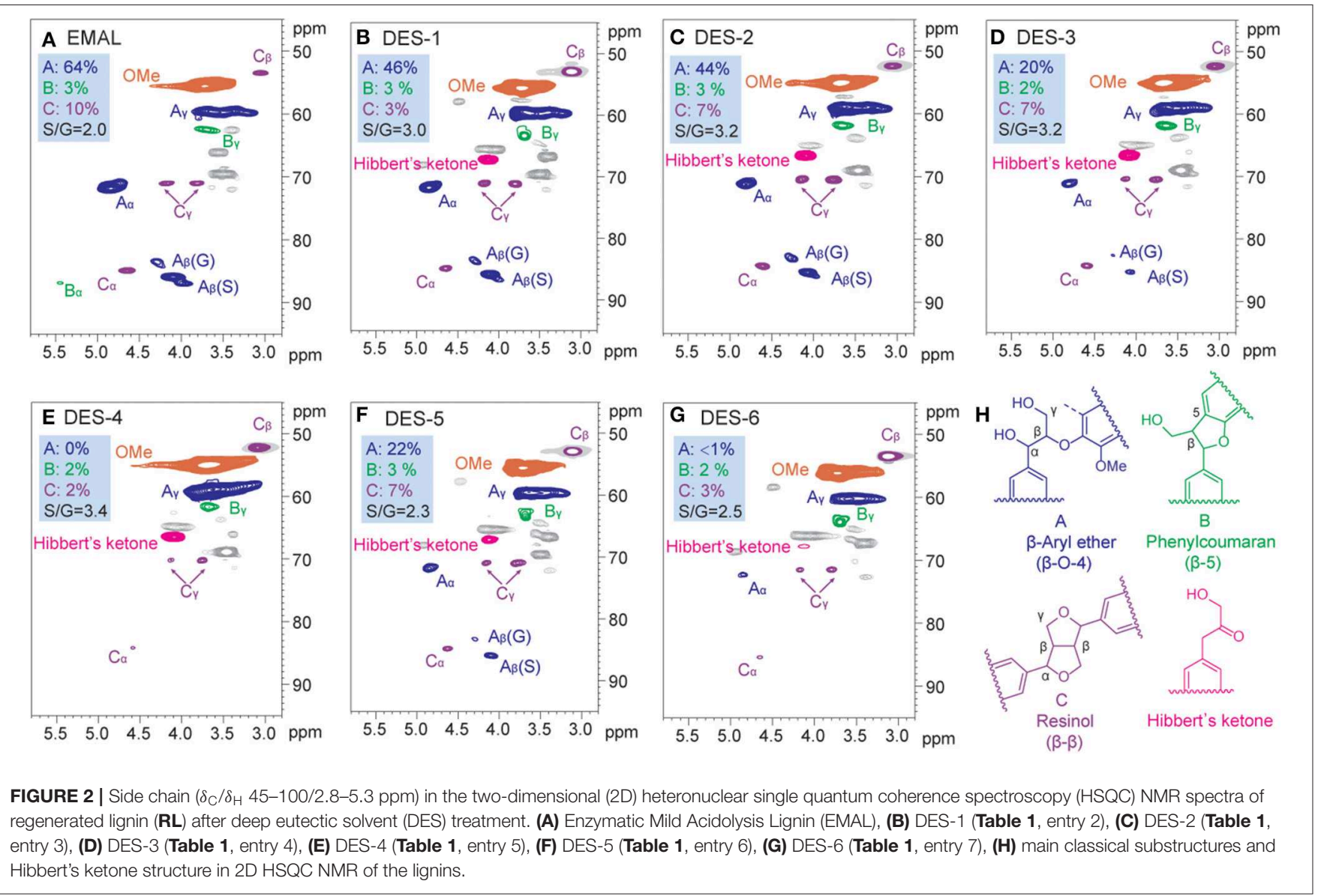

TABLE 1 | ChCI/LA DES-treated Eucalyptus EMAL under various reaction conditions (the unit of hydroxyl and carboxylic group: $\mathrm{mmol} / \mathrm{g})^{\mathrm{a}}$.

\begin{tabular}{|c|c|c|c|c|c|c|c|c|c|c|}
\hline \multirow[t]{2}{*}{ Entry } & \multirow[t]{2}{*}{ Samples } & \multirow[t]{2}{*}{$\mathbf{T}\left({ }^{\circ} \mathbf{C}\right)$} & \multirow[t]{2}{*}{$t(h)$} & \multicolumn{2}{|c|}{$\begin{array}{l}\text { Yield }^{\mathbf{b}} \\
\text { (wt\%) }\end{array}$} & \multirow[t]{2}{*}{ Aliphatic $\mathrm{OH}$} & \multirow{2}{*}{$\begin{array}{c}\text { Syringyl OH } \\
\overline{\mathrm{NC} / \mathrm{C}}\end{array}$} & \multirow{2}{*}{$\begin{array}{l}\text { Guaiacyl OH } \\
\frac{\mathrm{NC} / \mathrm{C}}{}\end{array}$} & \multirow[t]{2}{*}{ Total phenolic $\mathrm{OH}$} & \multirow[t]{2}{*}{ Carboxylic group } \\
\hline & & & & $\mathbf{R L}^{\mathrm{c}}$ & $\mathrm{FL}^{\mathrm{c}}$ & & & & & \\
\hline 1 & EMAL & - & - & - & - & 4.40 & $0.26 / 0.08$ & $0.40 / 0.06$ & 0.80 & 0.04 \\
\hline 2 & DES-1 & 80 & 1 & 86 & 10 & 3.90 & $0.22 / 0.09$ & $0.31 / 0.07$ & 0.69 & 0.08 \\
\hline 3 & DES-2 & 100 & 1 & 83 & 16 & 3.02 & $0.26 / 0.09$ & $0.34 / 0.07$ & 0.76 & 0.13 \\
\hline 6 & DES-5 & 100 & 2 & 74 & 11 & 3.20 & $0.30 / 0.10$ & $0.34 / 0.12$ & 0.86 & 0.26 \\
\hline 7 & DES-6 & 100 & 4 & 65 & 18 & 3.00 & $0.31 / 0.13$ & $0.36 / 0.19$ & 0.99 & 0.23 \\
\hline
\end{tabular}

${ }^{a}$ Reaction condition: EMAL (0.2 g), DES (2.0 g).

${ }^{D}$ The yield was calculated based on the mass ratio of $\boldsymbol{R} \boldsymbol{L}$ or $\boldsymbol{F L}$ to corresponding EMAL.

${ }^{c}$ The $\boldsymbol{R} \boldsymbol{L}$ (regenerated lignin) was obtained from precipitation with acid water $(\mathrm{pH}=2)$ after DES treatment; $\boldsymbol{F} \mathbf{L}$ (fragmented lignin) was extracted with dichloromethane from soluble fraction after DES treatment.

C, condensed; ChCl, choline chloride; DES, deep eutectic solvent; EMAL, enzymatic mild acidolysis lignin; LA, lactic acid; NC, non-condensed.

$0.53 \mathrm{mmol} / \mathrm{g})$ and DES-2 $\left(100^{\circ} \mathrm{C}, 0.60 \mathrm{mmol} / \mathrm{g}\right)$ at a relative low reaction temperature were comparable to initial EMAL $(0.66$ $\mathrm{mmol} / \mathrm{g}$ ), while significant increase of non-condensed $\mathrm{OH}$ was observed in DES-3 $\left(120^{\circ} \mathrm{C}, 1.01 \mathrm{mmol} / \mathrm{g}\right)$ and DES-4 $\left(140^{\circ} \mathrm{C}\right.$, $1.46 \mathrm{mmol} / \mathrm{g}$ ) at high temperatures. In the case of condensed $\mathrm{OH}$, a similar variation trend was also observed, and a maximum value of condensed $\mathrm{OH}$ was obtained in DES-4 $\left(140^{\circ} \mathrm{C}, 0.64\right.$ $\mathrm{mmol} / \mathrm{g}$ ). These results suggested that the lignin experiences depolymerization and repolymerization upon the cleavage of $\beta$ O-4 linkages in a synchronous manner, and both of them would be enhanced under harsh conditions, being in line with a previous report (Chen et al., 2019). Similar variation trends occurred in DES treatment time (DES-5 and DES-6). The carboxylic group, probably generated from oxidation reaction with DES, was also increased, especially with longer reaction time (DES-5, 0.26 $\mathrm{mmol} / \mathrm{g}$; DES-6, $0.23 \mathrm{mmol} / \mathrm{g}$ ). 
To elaborate the changes of inter-unit linkages, 2D HSQC NMR analysis for regenerated lignin samples DES-1 to DES6 were performed (Figure 2; see also Figure S3). The detailed signal peaks were assigned according to previous reports (Mansfield et al., 2012; Xiao et al., 2017). A decline of $\beta$-O4 linkage (46\%) was observed after DES treatment $80^{\circ} \mathrm{C}$ for $1 \mathrm{~h}$, being lower than that from EMAL (64\%). This decline was intensified with the rise of reaction temperature and/or time until almost all cross signals for $\beta$-O- 4 units disappeared in DES4 and DES-6. The lessening of $\beta-O-4$ linkage corresponded to the rise of phenolic hydroxyl groups. In the case of carboncarbon linkages ( $\beta-\beta$ and $\beta-5$ ), partial degradation was detected by comparison with those from EMAL. Thereby, the cleavage of $\beta-O-4$ linkage occurred preferentially in the DES treatment process. Of note, cross signals for Hibbert's ketone (labeled in red) were also detected in the regenerated lignin samples, which kept consistent in the conclusion that DES treatment process is an acid-catalyzed process (Brandt et al., 2015; Alvarez-Vasco et al., 2016; Das et al., 2018). Further analysis of HSQC NMR spectra showed that the signal intensity of Hibbert's ketone gradually decreased with prolonging reaction time until disappearance in DES-6 (Figure 2G) probably because Hibbert's ketone moiety could be released or retransformed.

The ratios of S/G subunits of regenerated lignin were also measured by semiquantitative integration of cross signals at aromatic/unsaturated region $\left(\delta_{\mathrm{C}} / \delta_{\mathrm{H}} 100-135 / 5.9-8.0 \mathrm{ppm}\right)$ (Figure 2 and Figure S3). The increased $S / G$ ratio values were detected after DES treatment by comparison with unreacted EMAL. The high ratios of S/G in regenerated lignin indicated that more guaiacyl subunits have been solubilized in fragmented lignin.

\section{Gel Permeation Chromatography and Gas Chromatography-Mass Spectrometry Analysis}

To address changes in lignin polymerization degree during DES treatment, analysis of the resulting samples by GPC was performed, as shown in Figure 3. The average $M_{w}$ slightly

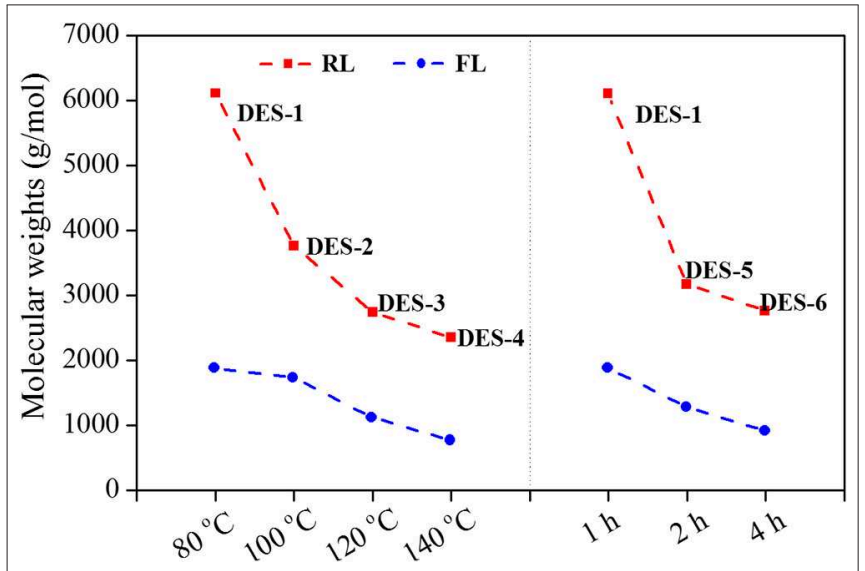

FIGURE 3 | Average molecular weight of regenerated lignin (RL) and fragmented lignin (FL). decreased from 8,590 g/mol for initial EMAL to $6,110 \mathrm{~g} / \mathrm{mol}$ for regenerated lignin sample DES-1, in line with the observation in $2 \mathrm{D}$ NMR spectra, where most $\beta$-O- 4 linkages still remained. The corresponding fragmented lignin recovered from soluble fraction showed a low $\mathrm{M}_{\mathrm{w}}$ of $1,890 \mathrm{~g} / \mathrm{mol}$. With the elevation of reaction temperature or time, the degree of lignin polymerization declined continuously. DES-4, obtained at $140^{\circ} \mathrm{C}$ and $1 \mathrm{~h}$, exhibited the lowest $M_{w}$ values of regenerated lignin $(2,350 \mathrm{~g} / \mathrm{mol})$ and fragmented lignin $(780 \mathrm{~g} / \mathrm{mol})$. Under such a condition, GPC corroborated the prevalence of full dissociation of lignin biopolymer, in alignment with NMR analysis, wherein highest abundance of hydroxyl groups and lowest content of $\beta$-O-4 moiety were both detected. In addition, the polydispersity values $\left(\mathrm{M}_{\mathrm{W}} / \mathrm{M}_{\mathrm{n}}\right)$ for regenerated lignin (1.35-1.57) and fragmented lignin (1.12-1.38) were both decreased compared to initial EMAL (2.08), indicating that the resulted lignin samples have a narrow distribution.
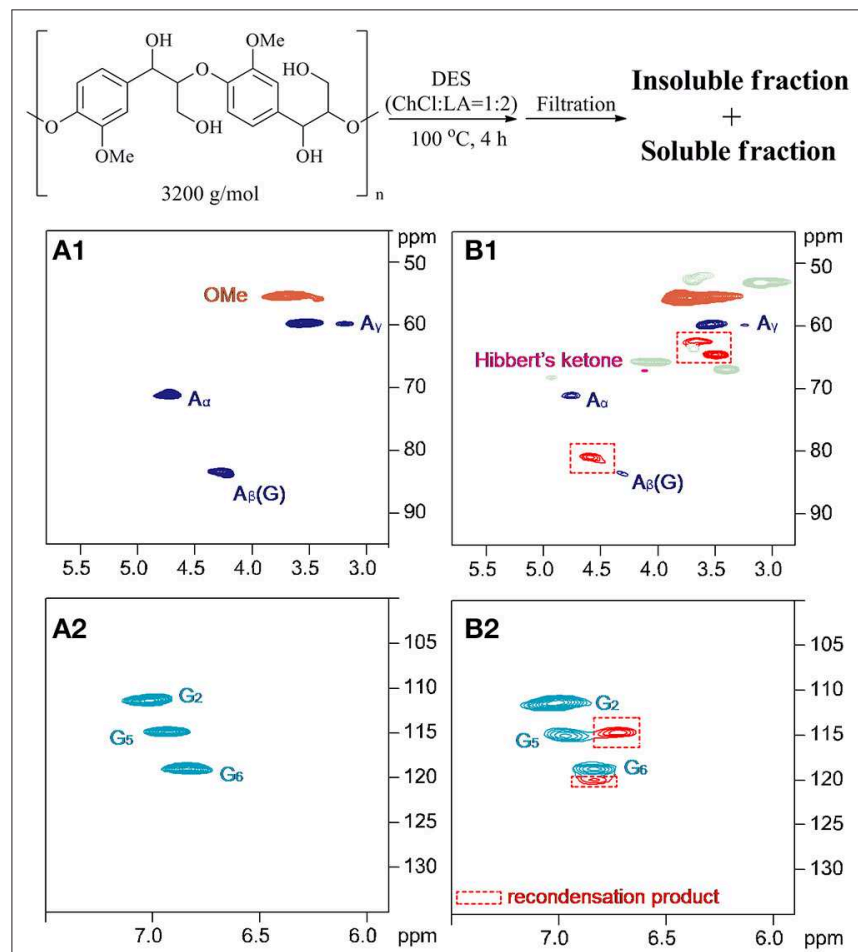

C

RL

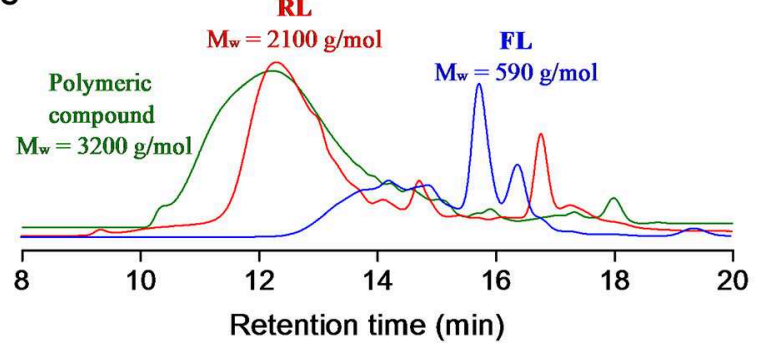

FIGURE 4 | Two-dimensional (2D) heteronuclear single quantum coherence spectroscopy (HSQC) spectra of (A) synthetic lignin polymeric compounds and (B) insoluble fraction after deep eutectic solvent (DES) treatment. (C) The molecular weight distribution. 
In view of the low polymerization degree in fragmented lignin, we speculated that some monomeric products have been generated. Product distributions based on GC-MS analysis showed that vanillin and syringaldehyde were produced as the major monomeric phenols in all cases. Interestingly, syringyland guaiacyl-derived monoketones and diketones were also detected (Figure S4), which were promoted with the rise of reaction temperature. It should be noted that either aldehyde or diketone derivatives from lignin depolymerization proceeded through an acid-catalyzed reaction according to previous reports (Lundquist and Hedlund, 1967; Deuss et al., 2015). Unfortunately, the combined yield of total monomers is less than $3 \mathrm{wt} \%$ by comparison with the authentic samples, which is rather lower than that from metal-catalyzed hydrogenolysis of EMAL (Xiao et al., 2017). The severe recondensation, which accompanies the depolymerization of lignin, may account for this scenario.

\section{Treatment of $\beta-0-4$ Mimics With Deep Eutectic Solvent}

Currently used EMAL contained $7 \mathrm{wt} \%$ carbohydrate, which, together with $\beta-\beta$ and $\beta-5$ linkages, will exhibit in the $2 \mathrm{D}$ NMR spectra after DES treatment and will disturb the distinction of lignin structure changes. To recognize the lignin-derived signals in a clear version, a synthetic polymer composed exclusively of the $\beta$-O- 4 substructure was treated with $\mathrm{ChCl} / \mathrm{LA} \mathrm{DES}$ at $100^{\circ} \mathrm{C}$ for $4 \mathrm{~h}$ (Figure 4A). The detailed workup procedure to acquire the soluble and insoluble fractions is similar with realistic lignin sample. For the case of insoluble fraction, the changes in $2 \mathrm{D}$ NMR spectra proceeded in a fashion akin to EMAL, that is, the sharp decline of $\beta$-O-4 signals and the emergence of Hibbert's ketone specie (Alvarez-Vasco et al., 2016; Das et al., 2018). Additionally, the cross peaks at aliphatic area (62.1/3.6 ppm,
64.3/3.5 ppm, 80.6/4.6 ppm), as well as at aromatic (114.6/6.7 ppm, 120.0/6.8 ppm), were emerged and detected (Figure 4B). Some of these signals could be found in NMR spectra of DEStreated EMAL (Figure 2). Taking into consideration the decline of $\beta$-O-4 moiety, together with current polymeric state, these new signals may be ascribed to the recondensation product (Shuai et al., 2010). This observation is different with previous report by using lignocellulosic biomass as substrates, where no condensation structures were distinguished probably because of the overlapping of signals (Alvarez-Vasco et al., 2016). The DEStreated $\beta-\mathrm{O}-4$ polymeric mimics also led to a decrease in $\mathrm{M}_{\mathrm{w}}$ from $3,200 \mathrm{~g} / \mathrm{mol}$ to $2,100 \mathrm{~g} / \mathrm{mol}$ (insoluble fraction) and $590 \mathrm{~g} / \mathrm{mol}$

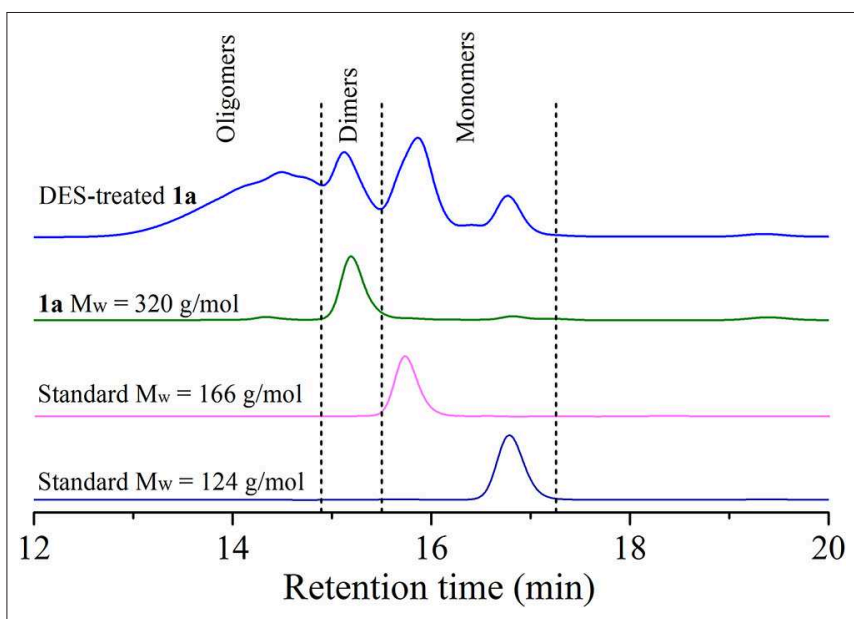

FIGURE 5 | Gel permeation chromatography (GPC) spectra of deep eutectic solvent (DES)-treated 1a, compound 1a and standard compounds [guaiacol: molecular weight $\left(M_{w}\right)=124 \mathrm{~g} / \mathrm{mol}$ and dihydroeugenol: $M_{w}=166 \mathrm{~g} / \mathrm{mol}$.

TABLE 2 | Product distribution of lignin $\beta-O-4$ dimeric compounds treatment with DES (ChCI/LA) ${ }^{\mathrm{a}}$.

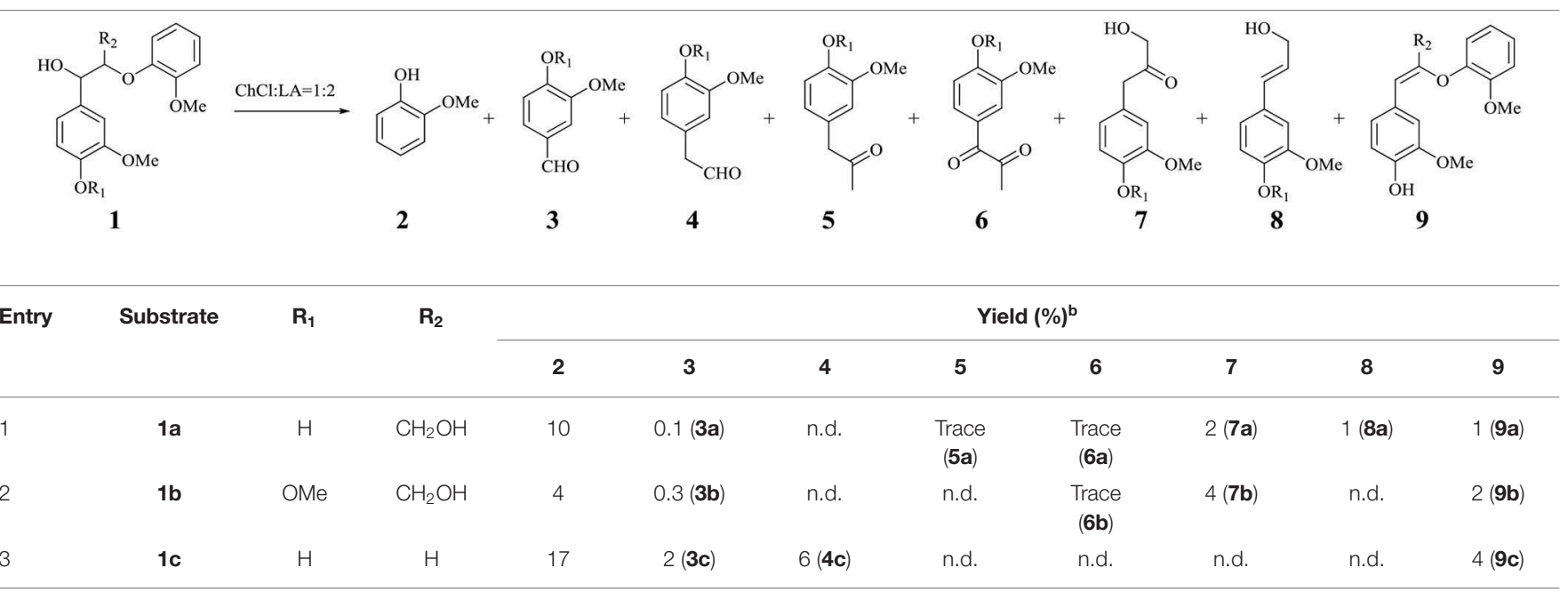

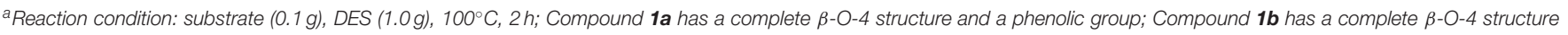
but lacks a non-phenolic group; Compound $1 \mathrm{c}$ is a phenolic model but is lacking $\gamma-\mathrm{CH}_{2} \mathrm{OH}$ in the $\beta$-O-4 structure.

${ }^{b}$ The yield was calculated based on the mole ratio of products to corresponding substrate by gas chromatography (GC)-mass spectrometry (MS).

ChCl, choline chloride; DES, deep eutectic solvent; LA, lactic acid; n.d., not detected. 
(soluble fraction) (Figure 4C). Further analysis of the soluble fraction suggested the vanillin, guaiacyl-derived monoketones, and diketone were all generated, being in line with scenario of realistic lignin (Figure S5).

A series of dimeric lignin mimics were also tested in DES at $100^{\circ} \mathrm{C}$ for $2 \mathrm{~h}$, and some representative results were summarized in Table 2 and Figure S6. Compound 1a, having a complete $\beta$-O- 4 structure and a phenolic group, underwent a full conversion after DES treatment. By comparison with authentic samples on GC-MS, some monophenols, such as vanillin (3a, $0.1 \%)$, guaiacyl-derived and Hibbert's ketone (7a, 2\%), coniferol (8a, 1\%), and guaiacol $(\mathbf{2}, 10 \%)$, were identified. It is worth mentioning that an enol ether derivative from dehydration reaction of 1a, which is often generated through an acid-catalyzed hydrolysis reaction and considered as intermediates toward Hibbert's ketone or aldehyde, was also observed in DES treatment (Table 2, entry 1) (Lundquist and Lundgren, 1972; Lundquist, 1976). Compared to metal catalysis systems (Hossain et al., 2019; $\mathrm{Li}$ and Song, 2019), the rather low mass balance from monomeric and dimeric products suggested that a severe repolymerization has occurred in DES treatment. The analysis of resulted mixture on LC-MS showed that trimers, tetramers, and oligomers with corresponding mass values have been generated, despite that the exact structures of the resulting products were hard to identify (Figure S7). GPC analysis of the resulting mixture indicated a broader polydispersity after compound 1a was treated with DES (Figure 5). A broad peak with a longer retention time (from 13.22 to $14.51 \mathrm{~min}$ ) appeared, which is assigned to oligomers in accordance with their larger molecular structure by comparison with compound 1a. The peak also having two shorter retention times (15.86 and $16.79 \mathrm{~min}$ ) corresponded to the monophenols. The above results confirmed that the depolymerization of $\beta-\mathrm{O}-4$ units and the repolymerization reactions occurred concurrently during DES treatment, being in accordance with realistic lignin and synthetic polymer. Given that few free phenolic groups exit in lignin before the cleavage of $\beta$-O- 4 unit, a non-phenolic model compound $\mathbf{1 b}$ with $\beta-\mathrm{O}-4$ structure was also tested by DES. This reaction gave similar monomeric products in lower yields (Table 2, entry 2), albeit a full conversion of $\mathbf{1 b}$ was observed. In the case of another phenolic lignin model 1c, which lacks $\gamma$ $\mathrm{CH}_{2} \mathrm{OH}$ in $\beta$-O-4 structure, aldehyde derivatives were generated as dominated monomers (Table 2, entry 3 ). Dimeric compounds

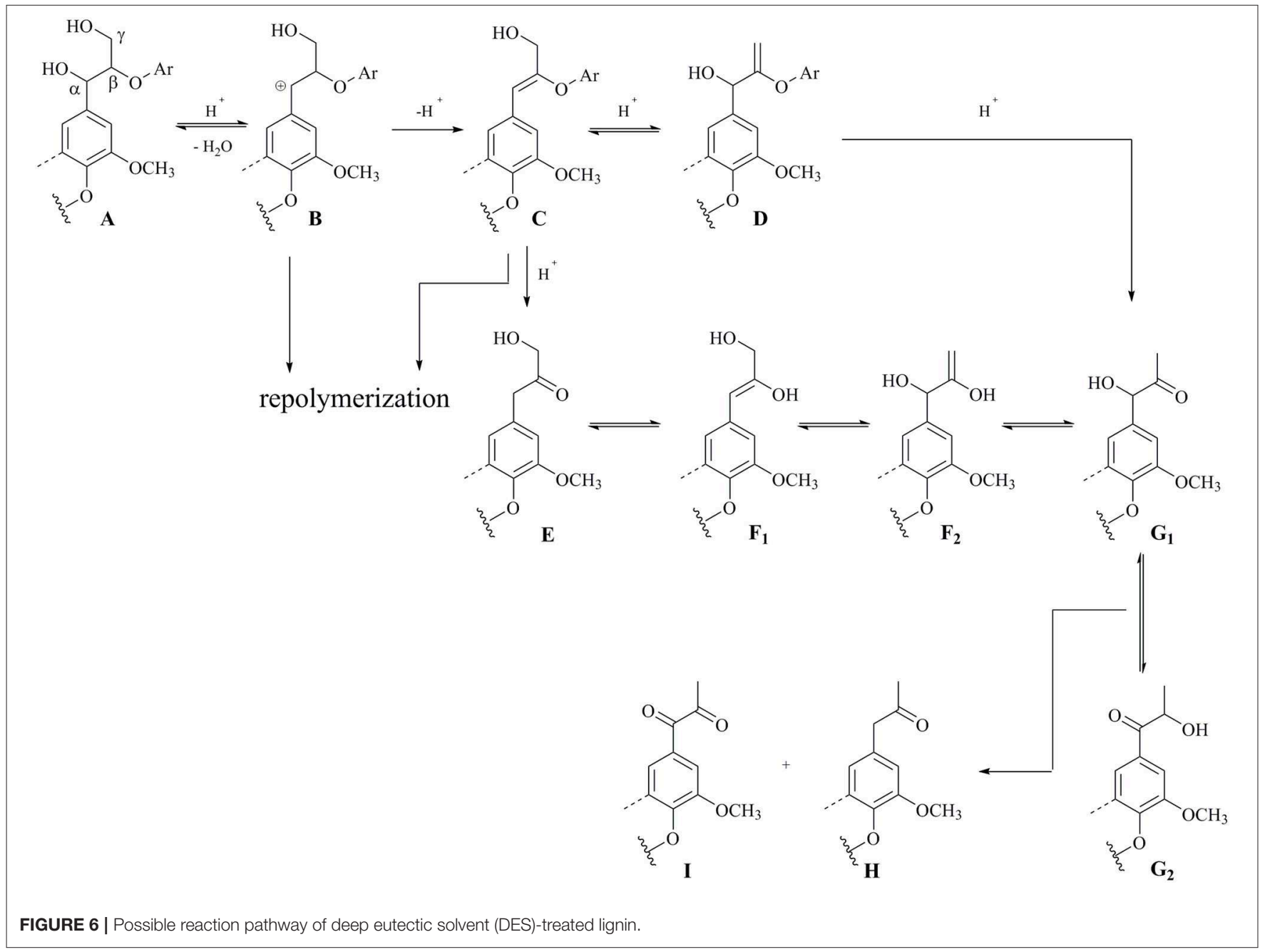


that do not contain complete $\beta-\mathrm{O}-4$ structure and methoxyl group on aromatic ring, i.e., phenethoxybenzene and 2-phenoxy1-phenylethanol, were also treated with $\mathrm{ChCl} / \mathrm{LA} \mathrm{DES}$, while no obvious conversion was detected (Figure S8).

\section{Plausible Reaction Pathway}

Based on the above results acquired from realistic lignin and model compounds, a plausible reaction pathway for the DEStreated lignin was proposed in Figure 6. $\beta-\mathrm{O}-4$ units in lignin should be efficiently cleaved probably through an acid-catalyzed process during DES. The reaction starts from a hydrogen ion attack on the $\alpha$-hydroxyl group in $\mathbf{A}$, which gives a carbocation species $\mathbf{B}$ via the release of one molecular unit of $\mathrm{H}_{2} \mathrm{O}$ (Lundquist and Lundgren, 1972; Lundquist, 1976; Ito et al., 2011; Sturgeon et al., 2014). The elimination reaction between $\alpha$ positive charge and $\beta-\mathrm{H}$ results in an enol ether intermediate $\mathrm{C}$, together with regeneration of a hydrogen ion. Following hydrolysis of $\mathrm{C}$ leads to the cleavage of $\mathrm{C}-\mathrm{O}$ bond, thus affording Hibbert's ketone moiety E (Lundquist and Lundgren, 1972; Lundquist, 1976; Ito et al., 2011; Sturgeon et al., 2014). Alternatively, allylic rearrangement of $\mathbf{C}$ forms isomeric enol ether $\mathbf{G} \mathbf{1}$ through D, and G1 can also be generated from the rearrangement reaction of $\mathbf{E}$ and $\mathbf{F}$ under acidic conditions (Lundquist and Hedlund, 1967). The isomerization of G1 intermediate gives G2 probably via an enediol, and an equilibrium is proposed between G1 and G2 (Lundquist and Hedlund, 1967; Lundquist and Lundgren, 1972). Finally, an oxidoreduction of the mixture $\mathbf{G} \mathbf{1}$ and $\mathbf{G} 2$ leads to the formation of monoketone $\mathbf{H}$ and diketone I (Lundquist and Hedlund, 1967; Lundquist and Lundgren, 1972). Experimental evidences have substantiated the formation of oligomers rapidly during DES treatment, which may derive from the fact that the carbocation $\mathbf{B}$ or enol ether $\mathbf{C}$ is most likely responsible for the repolymerization rather than depolymerization (Lohr et al., 2015; Li and Song, 2019).

\section{CONCLUSION}

The detailed structural transformation of lignin during DES (ChCl:LA, 1:2) treatment was systematically unraveled by means of experiments using isolated lignin and a series of $\beta-\mathrm{O}-4$ lignin model compounds. Entire fractions derived from lignin which were recovered from DES-treated EMAL showed different characteristics. The cleavage of $\beta-\mathrm{O}-4$ linkages of EMAL is exacerbated with the increasing of reaction temperature and/or time, which leads to a sustained fall of insoluble lignin fraction and average $M_{w}$ values, as well as a sustained rise of hydroxyl groups. The monomeric phenols derived from EMAL, polymeric and dimeric $\beta-\mathrm{O}-4$ mimics were also identified, albeit in low combined yields. Experimental evidences from the reactions of $\beta$-O-4 models substantiated that the repolymerization reaction is accompanied by the depolymerization process. Mechanistic study suggested the main steps during DES-treated wood lignin, such as the cleavage of $\beta-\mathrm{O}-4$, the repolymerization of active species, the production and derivation of mono products, should involve acid-catalyzed processes. This contribution provided a clear and beneficial information on lignin variation during DES treatment, which would be beneficial to design new DES-based pretreatment tailored for biorefinery and biotransformation.

\section{DATA AVAILABILITY STATEMENT}

All datasets generated for this study are included in the article/Supplementary Material.

\section{AUTHOR CONTRIBUTIONS}

SW carried out all experiments and wrote the manuscript. HL performed the lignin model compounds analysis. L-PX and GS designed the work and revised the manuscript. All authors discussed the results.

\section{FUNDING}

This work was supported by the National Natural Science Foundation of China (21776020, 31971607, 51961125207), the Natural Science Foundation of Liaoning Province (No. 2019-MS019), the Opening Project of Guangxi Key Laboratory of Clean Pulp \& Papermaking and Pollution Control (No. 2019KF14), and Youth Technology Talents of Dalian (No. 2019RQ035).

\section{SUPPLEMENTARY MATERIAL}

The Supplementary Material for this article can be found online at: https://www.frontiersin.org/articles/10.3389/fenrg. 2020.00048/full\#supplementary-material

\section{REFERENCES}

Alvarez-Vasco, C., Ma, R., Quintero, M., Guo, M., Geleynse, S., Ramasamy, K. K., et al. (2016). Unique low-molecular-weight lignin with high purity extracted from wood by deep eutectic solvents (DES): a source of lignin for valorization. Green Chem. 18, 5133-5141. doi: 10.1039/C6GC01007E

Behera, S., Arora, R., Nandhagopal, N., and Kumar, S. (2014). Importance of chemical pretreatment for bioconversion of lignocellulosic biomass. Renew. Sust. Energy Rev. 36, 91-106. doi: 10.1016/j.rser.2014. 04.047

Brandt, A., Chen, L., van Dongen, B. E., Welton, T., and Hallett, J. P. (2015). Structural changes in lignins isolated using an acidic ionic liquid water mixture. Green Chem. 17, 5019-5034. doi: 10.1039/C5GC01314C

Brosse, N., El Hage, R., Chaouch, M., Pétrissans, M., Dumarçay, S., and Gérardin, P. (2010). Investigation of the chemical modifications of beech wood lignin during heat treatment. Polym. Degrad. Stab. 95, 1721-1726. doi: 10.1016/j.polymdegradstab.2010.05.018

Chen, Z., Jacoby, W. A., and Wan, C. (2019). Ternary deep eutectic solvents for effective biomass deconstruction at high solids and low enzyme loadings. Bioresour. Technol. 279, 281-286. doi: 10.1016/j.biortech.2019.01.126

Chen, Z., Reznicek, W. D., and Wan, C. (2018). Aqueous choline chloride: a novel solvent for switchgrass fractionation and subsequent hemicellulose conversion into furfural. ACS Sust. Chem. Eng. 6, 6910-6919. doi: 10.1021/acssuschemeng.8b00728

Das, L., Li, M., Stevens, J., Li, W., Pu, Y., Ragauskas, A. J., et al. (2018). Characterization and catalytic transfer hydrogenolysis of deep eutectic solvent 
extracted sorghum lignin to phenolic compounds. ACS Sust. Chem. Eng. 6, 10408-10420. doi: 10.1021/acssuschemeng.8b01763

Deuss, P. J., Scott, M., Tran, F., Westwood, N. J., de Vries, J. G., and Barta, K. (2015). Aromatic monomers by in situ conversion of reactive intermediates in the acid-catalyzed depolymerization of lignin. J. Am. Chem. Soc. 137, 7456-7467. doi: 10.1021/jacs.5b03693

Galkin, M. V., and Samec, J. S. M. (2016). Lignin valorization through catalytic lignocellulose fractionation: a fundamental platform for the future biorefinery. ChemSusChem 9, 1544-1558. doi: 10.1002/cssc.201600237

Guerra, A., Filpponen, I., Lucia, L. A., Saquing, C., Baumberger, S., and Argyropoulos, D. S. (2006). Toward a better understanding of the lignin isolation process from wood. J. Agric. Food Chem. 54, 5939-5947. doi: 10.1021/jf060722v

Hossain, M. A., Phung, T. K., Rahaman, M. S., Tulaphol, S., Jasinski, J. B., and Sathitsuksanoh, N. (2019). Catalytic cleavage of the $\beta-O-4$ aryl ether bonds of lignin model compounds by Ru/C catalyst. Appl. Catal. A 582, 117100-117106. doi: 10.1016/j.apcata.2019.05.034

Ito, H., Imai, T., Lundquist, K., Yokoyama, T., and Matsumoto, Y. (2011). Revisiting the mechanism of $\beta$-O-4 bond cleavage during acidolysis of lignin. Part 3: search for the rate-determining step of a non-phenolic $\mathrm{C}_{6}-\mathrm{C}_{3}$ type model compound. J. Wood Chem. Technol. 31, 172-182. doi: 10.1080/02773813.2010.515050

Jeong, K. M., Lee, M. S., Nam, M. W., Zhao, J., Jin, Y., Lee, D.K., et al. (2015). Tailoring and recycling of deep eutectic solvents as sustainable and efficient extraction media. J. Chromatogr. A 1424, 10-17. doi: 10.1016/j.chroma.2015.10.083

Kim, K. H., Dutta, T., Sun, J., Simmons, B., and Singh, S. (2018). Biomass pretreatment using deep eutectic solvents from lignin derived phenols. Green Chem. 20, 809-815. doi: 10.1039/C7GC03029K

Li, H., and Song, G. (2019). Ru-catalyzed hydrogenolysis of lignin: base-dependent tunability of monomeric phenols and mechanistic study. ACS Catal. 9, 4054-4064. doi: 10.1021/acscatal.9b00556

Li, W., Amos, K., Li, M., Pu, Y., Debolt, S., Ragauskas, A. J., et al. (2018). Fractionation and characterization of lignin streams from unique high-lignin content endocarp feedstocks. Biotechnol. Biofuels 11, 304-317. doi: 10.1186/s13068-018-1305-7

Liu, Y., Chen, W., Xia, Q., Guo, B., Wang, Q., Liu, S., et al. (2017). Efficient cleavage of lignin-carbohydrate complexes and ultrafast extraction of lignin oligomers from wood biomass by microwave-assisted treatment with deep eutectic solvent. ChemSusChem 10, 1692-1700. doi: 10.1002/cssc.201601795

Lohr, T. L., Li, Z., and Marks, T. J. (2015). Selective ether/ester C-O cleavage of an acetylated lignin model via tandem catalysis. ACS Catal. 5, 7004-7007. doi: $10.1021 /$ acscatal.5b01972

Lundquist, K. (1976). Low-molecular weight lignin hydrolysis products. Appl. Polym. Symp. 28, 1393-1407

Lundquist, K., and Hedlund, K. (1967). Acid degradation of lignin I. the formation of ketones of the guaiacylpropane series. Acta Chem. Scand. 21, 1750-1754. doi: 10.3891/acta.chem.scand.21-1750

Lundquist, K., and Lundgren, R. (1972). Acid degradation of lignin part VII.* the cleavage of ether bonds. Acta Chem. Scand. 26, 2005-2023. doi: 10.3891/acta.chem.scand.26-2005

Lynam, J. G., Kumar, N., and Wong, M. J. (2017). Deep eutectic solvents' ability to solubilize lignin, cellulose, and hemicellulose; thermal stability; and density. Bioresour. Technol. 238, 684-689. doi: 10.1016/j.biortech.2017.04.079

Lyu, G., Li, T., Ji, X., Yang, G., Liu, Y., Lucia, A. L., et al. (2018). Characterization of lignin extracted from willow by deep eutectic solvent treatments. Polymers 10, 869-879. doi: 10.3390/polym10080869

Mansfield, S. D., Kim, H., Lu, F., and Ralph, J. (2012). Whole plant cell wall characterization using solution-state 2D NMR. Nat. Protoc. 7, 1579-1589. doi: $10.1038 /$ nprot.2012.064

Mbous, Y. P., Hayyan, M., Hayyan, A., Wong, W. F., Hashim, M. A., and Looi, C. Y. (2017). Applications of deep eutectic solvents in biotechnology and bioengineering-promises and challenges. Biotechnol. Adv. 35, 105-134. doi: 10.1016/j.biotechadv.2016.11.006

Meng, X., Crestini, C., Ben, H., Hao, N., Pu, Y., Ragauskas, A. J., et al. (2019). Determination of hydroxyl groups in biorefinery resources via quantitative ${ }^{31} \mathrm{P}$ NMR spectroscopy. Nat. Protoc. 14, 2627-2647. doi: $10.1038 / s 41596-019-0191-1$
Procentese, A., Johnson, E., Orr, V., Garruto Campanile, A., Wood, J. A., Marzocchella, A., et al. (2015). Deep eutectic solvent pretreatment and subsequent saccharification of corncob. Bioresour. Technol. 192, 31-36. doi: 10.1016/j.biortech.2015.05.053

Ragauskas, A. J., Beckham, G. T., Biddy, M. J., Chandra, R., Chen, F., Davis, M. F., et al. (2014). Lignin valorization: improving lignin processing in the biorefinery. Science 344:1246843. doi: 10.1126/science. 1246843

Rastogi, M., and Shrivastava, S. (2017). Recent advances in second generation bioethanol production: An insight to pretreatment, saccharification and fermentation processes. Renew. Sust. Energy Rev. 80, 330-340. doi: 10.1016/j.rser.2017.05.225

Satlewal, A., Agrawal, R., Bhagia, S., Sangoro, J., and Ragauskas, A. J. (2018). Natural deep eutectic solvents for lignocellulosic biomass pretreatment: recent developments, challenges and novel opportunities. Biotechnol. Adv. 36, 2032-2050. doi: 10.1016/j.biotechadv.2018.08.009

Shen, X.-J., Wen, J.-L., Mei, Q.-Q., Chen, X., Sun, D., Yuan, T.-Q., et al. (2019). Facile fractionation of lignocelluloses by biomass-derived deep eutectic solvent (DES) pretreatment for cellulose enzymatic hydrolysis and lignin valorization. Green Chem. 21, 275-283. doi: 10.1039/C8GC03064B

Shuai, L., Yang, Q., Zhu, J. Y., Lu, F. C., Weimer, P. J., Ralph, J., et al. (2010). Comparative study of SPORL and dilute-acid pretreatments of spruce for cellulosic ethanol production. Bioresour. Technol. 101, 3106-3114. doi: 10.1016/j.biortech.2009.12.044

Sluiter, A., Hames, B., Ruiz, R., Scarlata, C., Sluiter, J., Templeton, D., et al. (2008). Determination of Structural Carbohydrates and Lignin in Biomass. Golden, CO: National Renewable Energy Laboratory (NREL).

Smith, E. L., Abbott, A. P., and Ryder, K. S. (2014). Deep eutectic solvents (DESs) and their applications. Chem. Rev. 114, 11060-11082. doi: 10.1021/cr300162p

Song, G. (2019). The development of catalytic fractionation and conversion of lignocellulosic biomass under lignin-first strategy. J. For. Eng. 4, 1-10. doi: 10.13360 /j.issn.2096-1359.2019.05.001

Song, Y., Chandra, R. P., Zhang, X., Tan, T., and Saddler, J. N. (2019). Comparing a deep eutectic solvent (DES) to a hydrotrope for their ability to enhance the fractionation and enzymatic hydrolysis of willow and corn stover. Sust. Energy Fuels 3, 1329-1337. doi: 10.1039/C8SE00617B

Sturgeon, M. R., Kim, S., Lawrence, K., Paton, R. S., Chmely, S. C., Nimlos, M., et al. (2014). A mechanistic investigation of acid-catalyzed cleavage of aryl-ether linkages: implications for lignin depolymerization in acidic environments. ACS Sust. Chem. Eng. 2, 472-485. doi: 10.1021/sc400384w

Sun, Z., Fridrich, B., de Santi, A., Elangovan, S., and Barta, K. (2018). Bright side of lignin depolymerization: toward new platform chemicals. Chem. Rev. 118, 614-678. doi: 10.1021/acs.chemrev.7b00588

Tuck, C. O., Pérez, E., Horváth, I. T., Sheldon, R. A., and Poliakoff, M. (2012). Valorization of biomass: deriving more value from waste. Science 337, 695-699. doi: $10.1126 /$ science. 1218930

Vigier, K. D. O., Chatel, G., and Jérôme, F. (2015). Contribution of deep eutectic solvents for biomass processing: opportunities, challenges, and limitations. ChemCatChem 7, 1250-1260. doi: 10.1002/cctc.201500134

Wahlström, R., Hiltunen, J., Pitaluga de Souza Nascente Sirkka, M., Vuoti, S., and Kruus, K. (2016). Comparison of three deep eutectic solvents and 1-ethyl3-methylimidazolium acetate in the pretreatment of lignocellulose: effect on enzyme stability, lignocellulose digestibility and one-pot hydrolysis. RSC Adv. 6, 68100-68110. doi: 10.1039/C6RA11719H

Wang, H.-M., Wang, B., Wen, J.-L., Yuan, T.-Q., and Sun, R.-C. (2017). Structural characteristics of lignin macromolecules from different eucalyptus species. ACS Sust. Chem. Eng. 5, 11618-11627. doi: 10.1021/acssuschemeng.7b02970

Wang, S., Gao, W., Li, H., Xiao, L.-P., Sun, R.-C., and Song, G. (2018). Selective fragmentation of biorefinery corncob lignin into $p$-hydroxycinnamic esters with a supported zinc molybdate catalyst. ChemSusChem 11, 2114-2123. doi: $10.1002 /$ cssc. 201800455

Wu, S., and Argyropoulos, D. S. (2003). An improved method for isolating lignin in high yield and purity. J. Pulp Pap. Sci. 29, 235-240.

Wu, Y., Qian, Y., Lou, H., Yang, D., and Qiu, X. (2019). Enhancing the broad-spectrum adsorption of lignin through methoxyl activation, grafting modification, and reverse self-assembly. ACS Sust. Chem. Eng. 7, 15966-15973. doi: 10.1021 /acssuschemeng.9b02317

Xiao, L.-P., Wang, S., Li, H., Li, Z., Shi, Z.-J., Xiao, L., et al. (2017). Catalytic hydrogenolysis of lignins into phenolic compounds over carbon 
nanotube supported molybdenum oxide. ACS Catal. 7, 7535-7542. doi: 10.1021/acscatal.7b02563

Yang, H., Yoo, C. G., Meng, X., Pu, Y., Muchero, W., Tuskan, G. A., et al. (2020). Structural changes of lignins in natural populus variants during different pretreatments. Bioresour. Technol. 295, 122240-122246. doi: 10.1016/j.biortech.2019.122240

Zhang, C.-W., Xia, S.-Q., and Ma, P.-S. (2016). Facile pretreatment of lignocellulosic biomass using deep eutectic solvents. Bioresour. Technol. 219, 1-5. doi: 10.1016/j.biortech.2016.07.026

Zhang, Q., De Oliveira Vigier, K., Royer, S., and Jérôme, F. (2012). Deep eutectic solvents: syntheses, properties and applications. Chem. Soc. Rev. 41, 7108-7146. doi: $10.1039 / \mathrm{C} 2 \mathrm{CS} 35178 \mathrm{~A}$

Zhang, Y., Ni, S., Wang, X., Zhang, W., Lagerquist, L., Qin, M., et al. (2019). Ultrafast adsorption of heavy metal ions onto functionalized lignin-based hybrid magnetic nanoparticles. Chem. Eng. J. 372, 82-91. doi: 10.1016/j.cej.2019.04.111

Conflict of Interest: The authors declare that the research was conducted in the absence of any commercial or financial relationships that could be construed as a potential conflict of interest.

Copyright (c) 2020 Wang, Li, Xiao and Song. This is an open-access article distributed under the terms of the Creative Commons Attribution License (CC BY).

The use, distribution or reproduction in other forums is permitted, provided the original author(s) and the copyright owner(s) are credited and that the original publication in this journal is cited, in accordance with accepted academic practice. No use, distribution or reproduction is permitted which does not comply with these terms. 